\title{
Extrusion of Thermoplastic Starch: Effect of "Green" and Common Polyethylene on the Hydrophobicity Characteristics
}

\author{
Muhammad Pervaiz ${ }^{1,2}$, Philip Oakley ${ }^{1,3}$, Mohini Sain ${ }^{1,4,5}$ \\ ${ }^{1}$ Centre for Biocomposites and Biomaterials Processing, Faculty of Forestry, University of Toronto, Toronto, Canada \\ ${ }^{2}$ GreenCore Composites Inc., Sarnia, Canada \\ ${ }^{3}$ The Delphi Group, Ottawa, Canada \\ ${ }^{4}$ Centre of Advanced Chemistry, King Abdulaziz University, Jeddah, KSA \\ ${ }^{5}$ Mechanical Engineering Department, Luleå University of Technology, Luleå, Sweden \\ Email: " muhammad.pervaiz@utoronto.ca
}

Received 15 August 2014; revised 14 September 2014; accepted 27 September 2014

Copyright (C) 2014 by authors and Scientific Research Publishing Inc.

This work is licensed under the Creative Commons Attribution International License (CC BY).

http://creativecommons.org/licenses/by/4.0/

c) (i) Open Access

\begin{abstract}
Novel plastics that are biodegradable, environmentally benign, and made from renewable natural resources are currently being researched as alternatives to traditional petroleum-based plastics. One such plastic, thermoplastic starch (TPS) is produced from starch processed at high temperatures in the presence of plasticizers, such as water and glycerol. However, because of its hydrophilic nature, TPS exhibits poor mechanical properties when exposed to environmental conditions, such as rain or humidity. The overall objective of this research work was to produce a thermoplastic starch based material with low water absorption that may be used to replace petroleumbased plastics. With a recent emergence of "green" polyethylene (GPE), sourced from renewable feedstock, it has become possible to develop novel biodegradable polymers for various applications. In this work, GPE was melt blended with starch in three different ways; reactive extrusion of GPE and starch facilitated by maleic anhydride (MAH) and dicumyl peroxide (DCP), melt blending of GPE and starch by extrusion, and melt blending of maleated polyethylene and starch by extrusion. Comprehensive testing and analysis has shown that all methods reduced water absorption significantly with some variations across the board.
\end{abstract}

\section{Keywords}

Biopolymers, Thermoplastic Starch, Biodegradable, Green Polyethylene, Hydrophobic, Water Absorption, Melt-Blending of Starch, Renewable Resources

\footnotetext{
*Corresponding author.
}

How to cite this paper: Pervaiz, M., Oakley, P. and Sain, M. (2014) Extrusion of Thermoplastic Starch: Effect of "Green" and Common Polyethylene on the Hydrophobicity Characteristics. Materials Sciences and Applications, 5, 845-856. 


\section{Introduction}

Over the past century the petroleum-based polymer industry has grown rapidly by creating materials that are cheap, easy to transform, hydrophobic, and biologically inert. However, several decades of using and disposing of non-biodegradable plastic has caused an accumulation of plastic waste in landfills, polluted maritime environments, and contributed to the depletion of our limited reserves of fossil fuels. In a recent marine pollution study, a staggering amount of 4256 plastic pieces per square $\mathrm{km}$ of ocean surface were observed, whereas up to 800 different kinds of waste marine plastics, mostly micro-sized pieces, were also recorded in same work [1]. One alternative to disposing these plastics in landfills is burning them for energy production. However, this merely moves pollution from ground level into the atmosphere in the form of carbon dioxide and other gases. Recycling also has the problem of being energy intensive and requiring selective sorting out and cleaning of waste plastic [2]. A better alternative is to minimize the quantities of non-degradable plastics used by substituting them with biodegradable plastics.

Starch has attracted attention as a suitable material for the production of biodegradable plastics due to its natural abundance and low cost [3] [4]. Starch is produced naturally during photosynthesis in plants, usually potatoes, corn, and rice [5], and functions as the principal polysaccharide reserve material, deposited in the form of complex structures called granules [6] [7]. The two main constituents of starch granules are the polysaccharides amylopectin and amylose, composed of repeating units of $\alpha$-D-glucose, Figure 1 . The major component of most starches is amylopectin and it constitutes about 70\% of the polysaccharide content [8] [9].

The $\mathrm{OH}$ functional group is susceptible to substitution reactions and has a high affinity for water, causing much of the problem of water absorption in starch formulations. Also, the C-O-C bond is susceptible to chain breakage [6]. A number of chemical reactions with these two groups have been studied in the literature to increase the hydrophobicity of starch [7].

Plasticized starch or thermoplastic starch (TPS) is prepared under specific extrusion conditions and in the presence of plasticizers, such as glycerol and water [10]-[12]. Some researchers have tried to improve the water resistance of TPS by melt-blending starch with hydrophobic polymers, while maintaining the biodegradability of the overall product. Hydrophobic and biodegradable polymers such as poly(e-caprolactone) [13], cellulose acetate [14], poly(butylene adipate-co-terephthalate) [15], and polylactides [16] have shown to be valuable candidates for melt-blending with TPS; however, use of these biodegradable polymers in commercial applications is restricted by their relatively high cost and poor mechanical properties compared to commodity plastics such as polyethylene (PE) and polypropylene. Researchers have also reported a low moisture absorbing TPS manufactured from a native starch using a polysaccharide produced by the fungus species Ophiostomaulmi; the modified

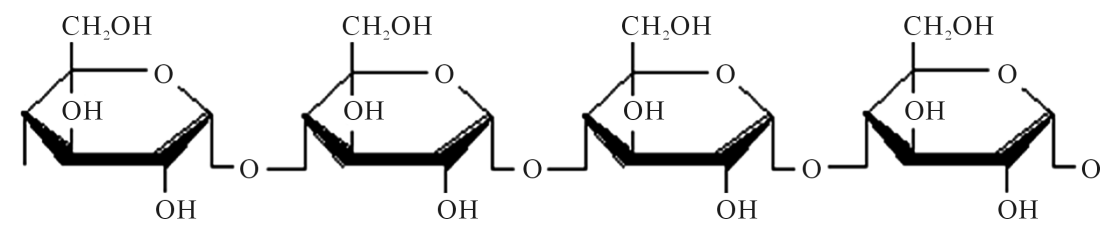

(a)
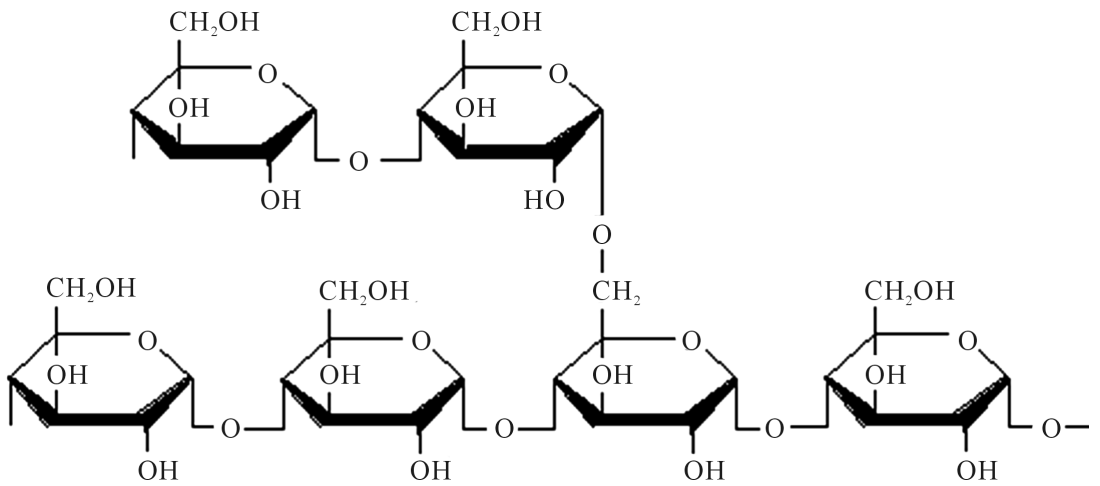

(b)

Figure 1. Structure of the amylose (a) and amylopectin (b) starch polymers [9]. 
TPS being of high tensile strength and capable to be transformed into films or molding products by casting, extrusion, injection, or compression molding techniques [17].

Melt blending of starch with non-biodegradable polymers such as PE is a good way of improving TPS properties, but PE contents must be kept low to ensure biodegradability of the blend [18]. A new form of PE, called green polyethylene, has recently become available on the market. It is produced from the renewable material sugarcane; therefore, it seems to be a suitable material to melt-blend with starch from a marketing ("green" materials) and environmental perspective.

Developing melt-blends with satisfactory properties depends on the ability to generate a small dispersed phase size with strong interfacial adhesion, thereby improving the stress transfer between the component phases [19]. This is accomplished by using a compatibilizer that reacts with the hydroxyl groups of starch to form covalent bonds, providing interfacial adhesion [20]. Common compatibilizers used in starch mixtures are ethyleneeacrylic acid (EAA), maleic anhydride (MAH), and ethylene vinyl alcohol (EVA). MAH is the most suitable of these compatibilizers because EVA is hydrophilic and the moisture it attracts is detrimental to TPS's mechanical properties. Also, a large amount of EAA is required for compatibilization which becomes costly [21]. The reactions whereby MAH reacts with PE to form maleated PE which then reacts with starch are shown below in Figure 2 and Figure 3, respectively.

Reactive extrusion is the simplest and most cost effective method for carrying out this two-step reaction. High temperature extrusion, usually using a twin screw extruder, is a main component of this process which accomplishes both of these reactions in a single step; thereby eliminating the need for two separate extrusion steps and ensuring reduced production costs [22]. Researchers in the past have studied the extrusion of starch with PE and found that blends containing MAH showed higher tensile strength, elongation at break, and thermal stability than those of blends without MAH [21], however no comparative studies are found on extruded starch/PE/MAH with starch/maleated PE blends involving water absorption analysis.

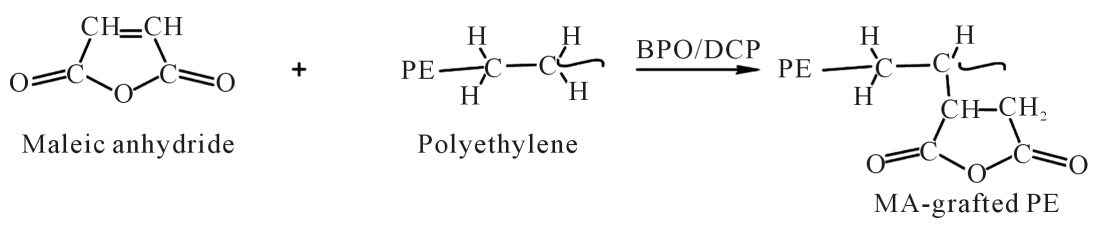

Figure 2. Reaction of MAH with PE initiated by DCP or BPO5.<smiles>CCCCC1CCC(=O)OC1=O</smiles>

MA-grafted PE
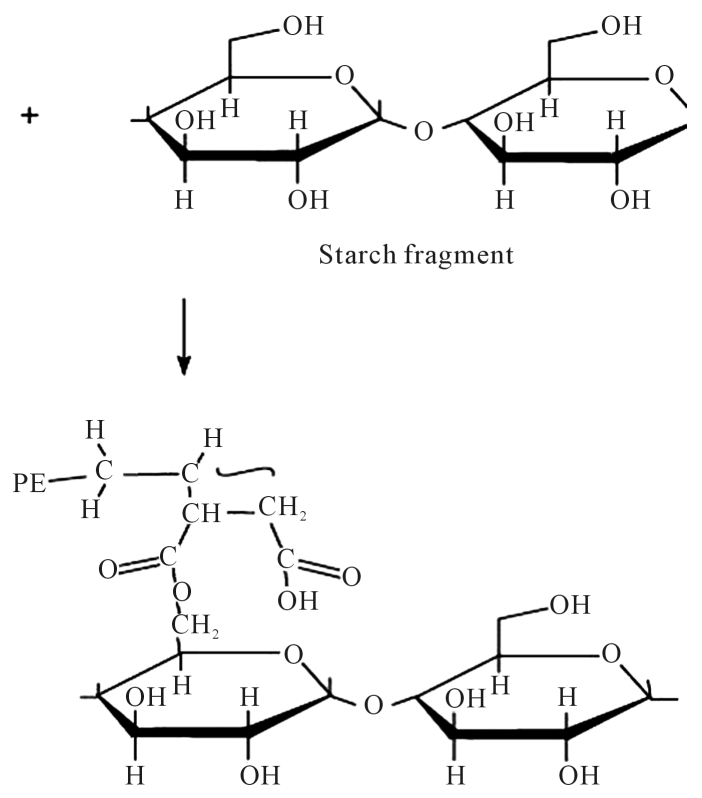

Starch-MA-grafted PE blend

Figure 3. Reaction of maleated PE with starch. 
In this current work, an effort has been made to reduce water absorption in TPS by blending with polyethylene through three different ways; reactive extrusion of green polyethylene and starch facilitated by MAH and DCP, melt blending of green polyethylene and starch by extrusion, and melt blending of maleated polyethylene and starch by extrusion.

\section{Experimental}

\subsection{Materials}

Industrial grade cornstarch (11\% moisture) was obtained from Casco Inc. (Cardinal, ON, Canada). Glycerol was purchased from ACP Chemicals Inc. (Montreal, QC). Green polyethylene DA-5800 (GPE) was supplied by Braskem S.A (Sao Paulo, Brazil) and maleated polyethylene (MPE) by Arkema Inc. (Philadelphia, PA). Maleic anhydride (MAH) and dicumyl peroxide (DCP) were purchased from Sigma-Aldrich (Oakville, ON).

\subsection{Plasticization}

Starch, glycerol, and water were mixed with a high speed kitchen mixer for $30 \mathrm{~min}$. MPE or GPE, MA, and DCP were added and mixed for an additional $10 \mathrm{~min}$. Compositions of the ten samples prepared are listed below in Table 1.

The plasticization was done through a twin screw extruder, TSE 25/40, available at Center for Biocomposites and Biomaterials Processing (CBBP), University of Toronto, Canada. A representative diagram of the extruder is shown in Figure 4, whereas, the temperature profile along the extruder barrel (from feed zone to die) is given in Table 2.

\subsection{FTIR}

The study on the functional groups of GPE and MGPE was performed on a Bruker Tensor-27 spectrometer. All spectra were captured over a range of 400 to $4000 \mathrm{~cm}^{-1}$ at a resolution of $4 \mathrm{~cm}^{-1}$ with 200 scans. To investigate the reactivity of maleic anhydride with green polyethylene, GPE was extruded separately at the same processing

\section{Table 1. Weight proportions of sample compositions.}

\begin{tabular}{|c|c|c|c|c|c|c|c|}
\hline \multirow{2}{*}{ Sample } & \multicolumn{7}{|c|}{ Weight Proportion (w/w\%) } \\
\hline & Starch & Glycerol & Water & GPE & MPE & МAH & DCP \\
\hline TPS & 100 & 45 & 30 & 0 & 0 & 0 & 0 \\
\hline $5 \mathrm{GPE}$ & 100 & 45 & 30 & 5 & 0 & 0 & 0 \\
\hline $10 \mathrm{GPE}$ & 100 & 45 & 30 & 10 & 0 & 0 & 0 \\
\hline $20 \mathrm{GPE}$ & 100 & 45 & 30 & 20 & 0 & 0 & 0 \\
\hline 5 MGPE & 100 & 45 & 30 & 5 & 0 & 0.05 & 0.005 \\
\hline $10 \mathrm{MGPE}$ & 100 & 45 & 30 & 10 & 0 & 0.1 & 0.01 \\
\hline 20 MGPE & 100 & 45 & 30 & 20 & 0 & 0.2 & 0.02 \\
\hline $5 \mathrm{MPE}$ & 100 & 45 & 30 & 0 & 5 & 0 & 0 \\
\hline $10 \mathrm{MPE}$ & 100 & 45 & 30 & 0 & 10 & 0 & 0 \\
\hline $200 \mathrm{MPE}$ & 100 & 45 & 30 & 0 & 20 & 0 & 0 \\
\hline
\end{tabular}

Table 2. Temperature profile used for extrusion from feed throat to exit-die.

\begin{tabular}{cccccccccccc}
\hline & \multicolumn{1}{c}{ Zone } \\
\cline { 2 - 9 } & 1 & 2 & 3 & 4 & 5 & 6 & 7 & 9 \\
\hline Temperature $\left({ }^{\circ} \mathrm{C}\right)$ & 155 & 155 & 155 & 160 & 160 & 160 & 160 & 165 & 170 \\
\hline
\end{tabular}




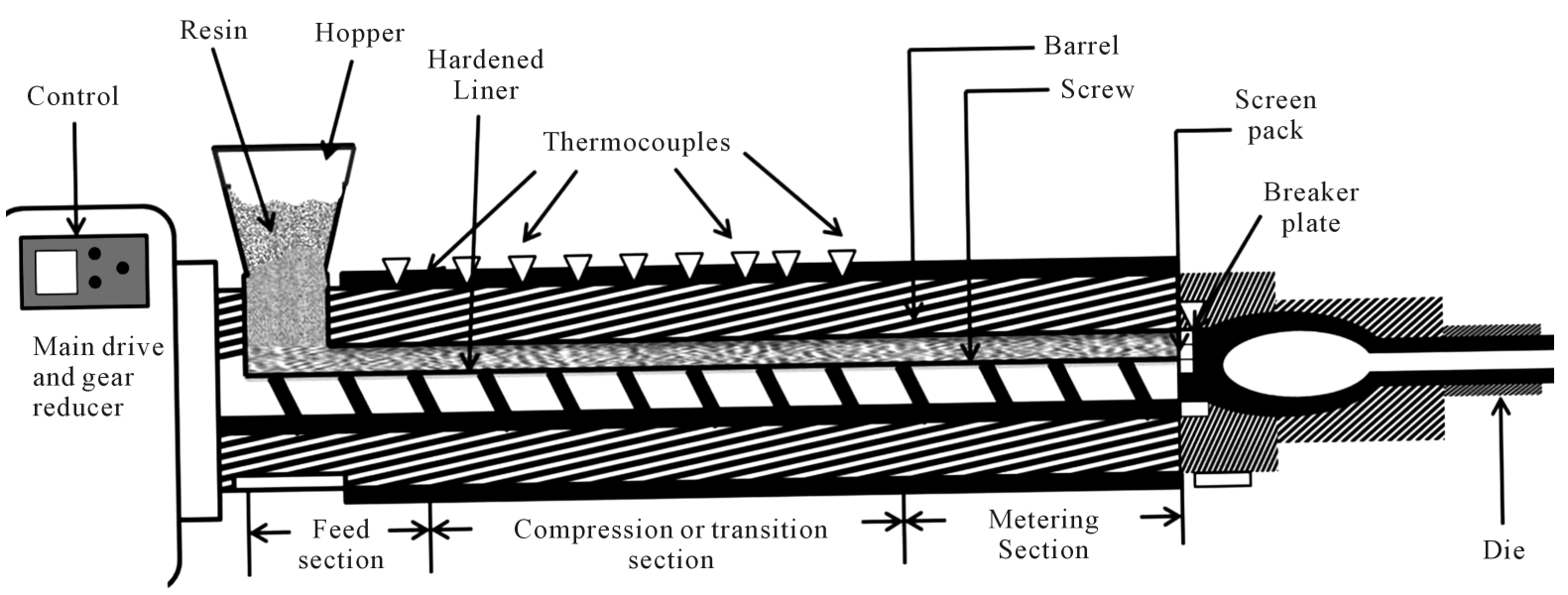

Figure 4. Schematic of twin screw extruder used for plasticization.

conditions and in the presence of MAH and DCP. The extrudate was purified to remove any unreacted MAH by dissolution of PE in xylene followed by precipitation in acetone.

\subsection{SEM}

Specimens were fractured with a knife and the exposed surfaces were observed with a JEOL JSM-840 scanning electron microscope (Tokyo, Japan). All surfaces were coated with gold to avoid charging under the electron beam. The electron gun voltage was set at $15 \mathrm{kV}$. The micrographs of samples were taken at magnifications of 200 to identify cracks, holes and other changes on the surface of the samples.

\subsection{TGA}

The thermal properties of the blends were measured with a TGA Q500 type thermal analyzer purchased from TA Instruments (New Castle, DE). Sample weight varied from 1 to $5 \mathrm{mg}$. Samples were heated on a platinum pan from ambient temperature to $600^{\circ} \mathrm{C}$ at a heating rate of $15^{\circ} \mathrm{C} / \mathrm{min}$. Results shown for each sample are from a single measurement. Derivatives of TGA thermograms were obtained using TA Instruments Universal Analysis software.

\subsection{Water Absorption}

Water absorption (WA) of each sample was measured by first preparing $2 \times 2$ square inch thin film specimens using a model ARG-450 hydraulic press supplied by Dieffenbacher N.A. Inc. (Windsor, ON). Samples were pressed for $4 \mathrm{~min}$ at $160^{\circ} \mathrm{C}$ and $500 \mathrm{kPa}$, cut into square specimens, and dried overnight in a desiccator. Dried specimens were placed in a desiccator containing distilled water at room temperature $\left(23^{\circ} \mathrm{C}, 100 \% \mathrm{RH}\right)$ and weighed every $24 \mathrm{~h}$. WA of each specimen was calculated by the following equation:

$$
\mathrm{WA}=\frac{\mathrm{W}_{\mathrm{a}}-\mathrm{W}_{\mathrm{i}}}{\mathrm{W}_{\mathrm{i}}}
$$

where $\mathrm{W}_{\mathrm{a}}$ is the weight of the specimen at a specific time interval and $\mathrm{W}_{\mathrm{i}}$ is the initial dry weight of the specimen. Equilibrium was assumed to be reached when the difference between successive WA values was less than $1 \%$. The result of each sample represents the average of five specimens.

\section{Results and Discussion}

\subsection{FTIR}

Maleic anhydride, after grafting onto PE, exists in the form of succinic anhydride. In FTIR spectra the presence of 5 membered anhydride rings, such as succinic anhydride is shown by a peak in the area of $1790 \mathrm{~cm}^{-1}$. If any unreacted MAH remains after the purification it is shown by the peak at $698 \mathrm{~cm}^{-1}$, attributed to the $\mathrm{C}=\mathrm{C}$ bond in 


\section{MAH [21].}

Figure 5 exhibits the spectra for unreacted green polyethylene and green polyethylene extruded with MAH and DCP. In the reacted sample, a peak at $1790 \mathrm{~cm}^{-1}$ caused by the asymmetrical stretching vibration bond of anhydride groups is present. This verified the fact that MAH grafted onto GPE in the presence of DCP, and may be used as compatibilizer in TPS/GPE blends during extrusion. The spectrum for the unreacted GPE shows no peaks at $1790 \mathrm{~cm}^{-1}$ and $698 \mathrm{~cm}^{-1}$. This indicates that there are no anhydride groups in the sample, as expected.

\subsection{Morphology Study}

The SEM image of TPS at $100 \times$ magnification is shown in Figure 6. The image mostly represents a smooth surface with some roughness and pits caused by the physical slicing during sample preparation and due to some unplasticizedstarch granules. This kind of TPS imagery is supported in literature by others [23].

Figure 7 represents SEMs of different blends of starch and GPE samples. Some starch particles remained unplasticized and were removed from the surface of the blends during the fracture of the specimen, leaving some pits in the fracture surface, clearly visible at 500× magnification in Figure 7(b). There appears to be phase separation between starch and GPE in all samples, more prominent at a higher GPE content, Figure 7(c). This lead to the fact of poor interfacial adhesion between TPS and GPE due to processing of structurally dissimilar polymers [4].

The SEM images of the MGPE samples are shown in Figure 8. As with the GPE samples, some starch particles remained unplasticized and are visible in the images, especially in Figure 8(c). In this case, the addition of MAH has enabled a continuous phase among TPS and GPE due to better compatibility.

Shown in Figure 9 are SEM images of the MPE samples. Again, some starch particles remained unplasticized likely from MPE interference as explained above. TPS and MPE combined in a mostly continuous phase as with

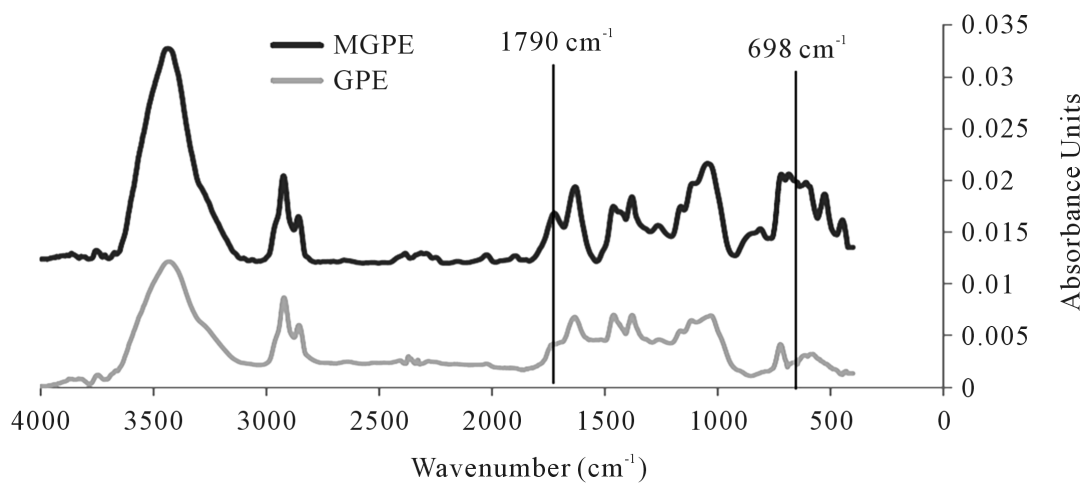

Figure 5. FTIR spectrum for GPE and MGPE.

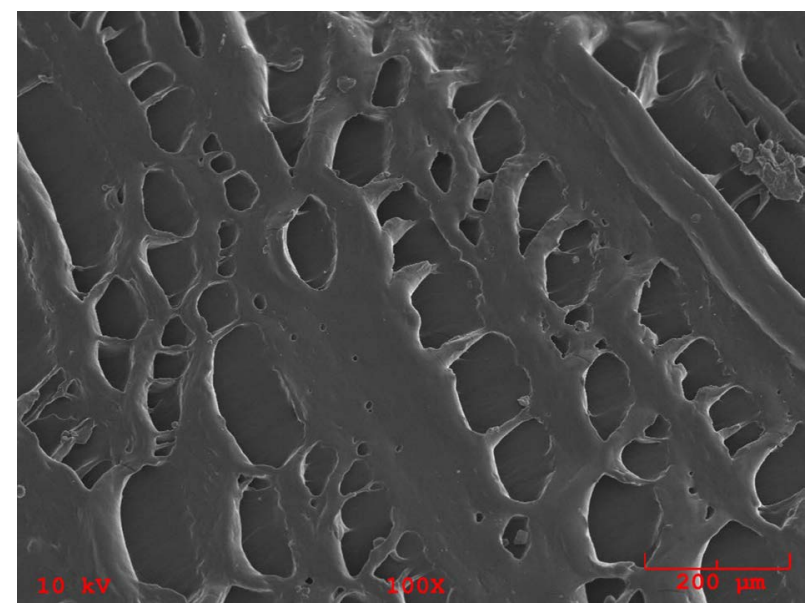

Figure 6. SEM image of TPS sample. 


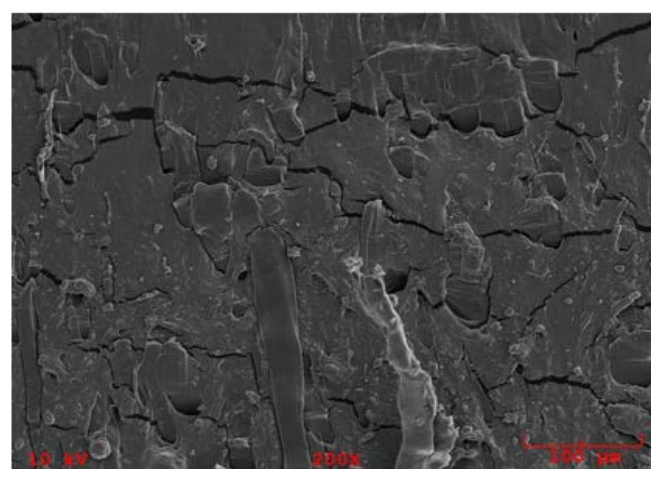

(a)

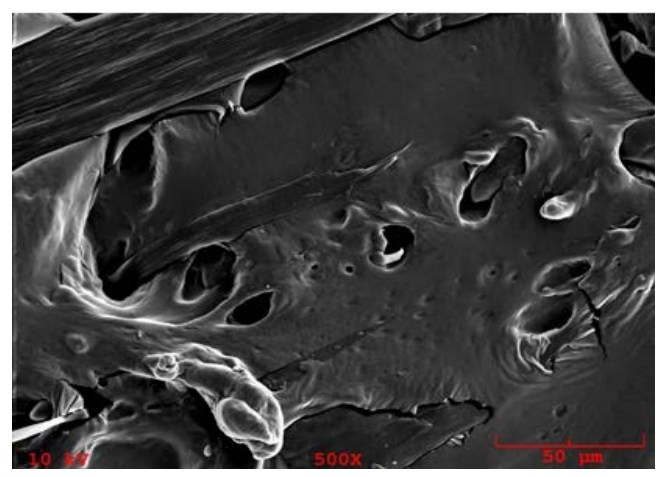

(b)

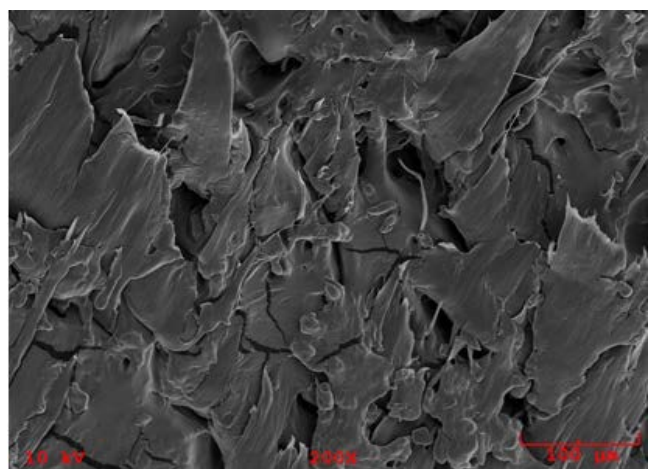

(c)

Figure 7. SEM images of extruded samples: (a) 5 GPE; (b) 10 GPE; (c) 20 GPE.

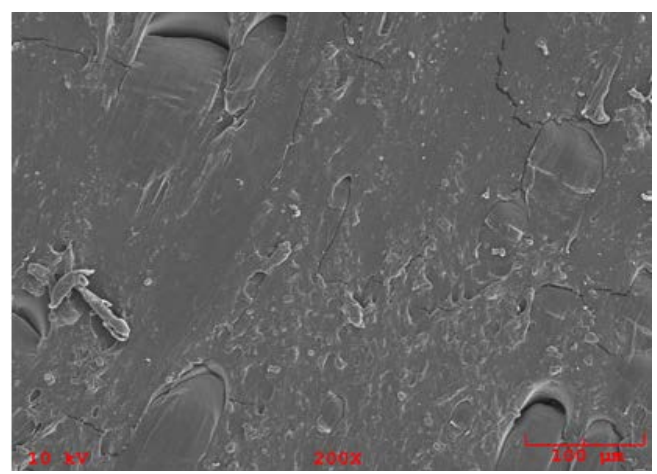

(a)

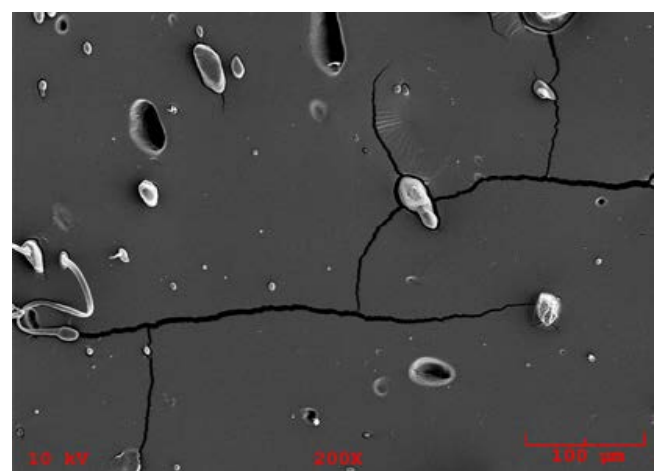

(b)

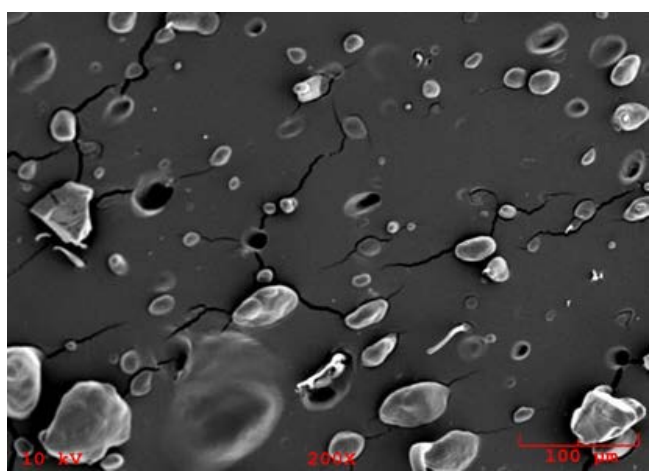

(c)

Figure 8. SEM images of extruded samples: (a) 5 MGPE; (b) 10 MGPE; (c) 20 MGPE. 


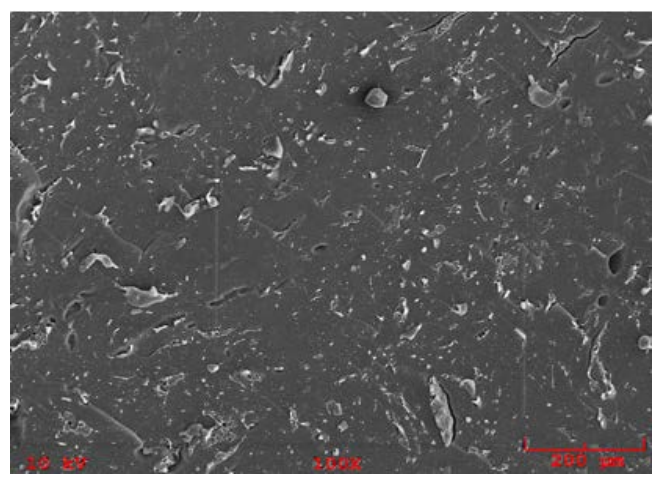

(a)

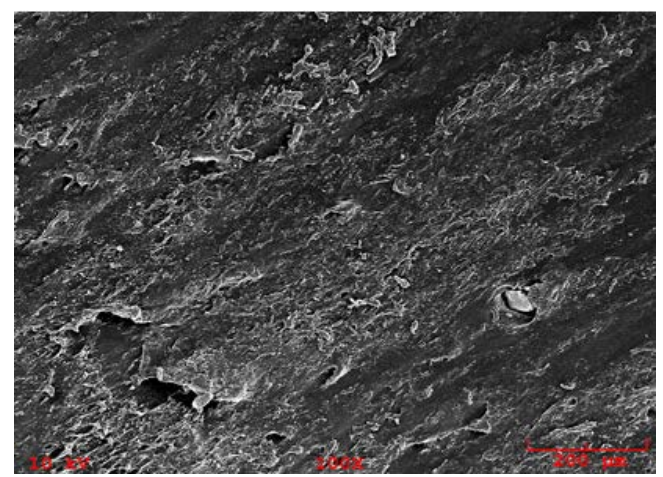

(b)

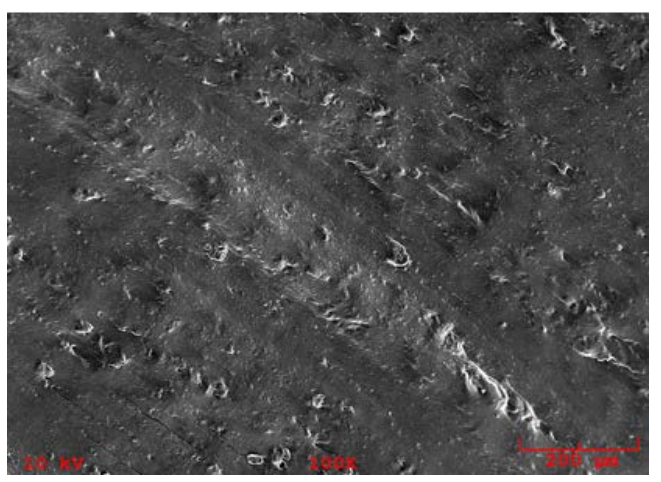

(c)

Figure 9. SEM images of MPE samples: (a) 5 MPE; (b) 10 MPE; (c) 20 MPE.

the MGPE samples. Again, this was a result of maleic anhydride improving the compatibility between TPS and PE.

\subsection{Thermal Analyses}

TGA results for all blended samples are shown in Figure 10(a)-(c) where GPE and TPS curves serve as reference data. In the case of all GPE, MGPE, and MPE samples, there were three well defined shifts in the TGA curve. First, at around $100^{\circ} \mathrm{C}$, water evaporation and unreacted MAH sublimation (in the case of MGPE) caused the initial weight loss. Weight loss continued gradually as water continued to evaporate along with glycerol (starting at $150^{\circ} \mathrm{C}$ ). A second major shift occurred from $300^{\circ} \mathrm{C}$ to $350^{\circ} \mathrm{C}$ where the thermal degradation of starch occurred. Finally, the third shift was a result of PE degradation beginning at $450^{\circ} \mathrm{C}$.

Derivative TGA curves for all PE/TPS samples are shown in Figure 11(a)-(c) with PE and TPS as references.

Table 3 represents the data extracted from the derivative TGA curves for all pure polymers and TPS blends tested. $\mathrm{T}_{5 \%}$, the temperature corresponding to $5 \%$ weight loss of the sample showed no discernable trend with respect to amount or type of PE for the GPE and MPE samples. However, for the MGPE samples the $T_{5 \%}$ values increased with the amount of PE, indicating an increase in stability of the blends. Perhaps this trend was not seen for the GPE and MPE samples because these blends were not as compatible; therefore, increasing the amount of PE in these samples did not further increase the stability of the blends because the PE portion was not strongly associated with the less thermally stable starch portion.

Starch $\mathrm{T}_{\max }$ and PE $\mathrm{T}_{\max }$ values correspond to the maximum rate of degradation for starch and PE, respectively. There was no trend evident in the starch $T_{\max }$ values for the blended samples, which all have a $T_{\max }$ value close to that of TPS. Therefore, it does not appear that any significant starch degradation occurred in all three types of TPS/PE blends. PE $\mathrm{T}_{\max }$ values for the MPE blended samples are similar to the value for pure MPE, indicating no PE degradation.

An interesting phenomenon was observed in the derivative TGA curves for the GPE and MGPE blended samples. The derivative TGA curves for pure GPE and MGPE displayed a wide degradation temperature range as a result of the composition of GPE. GPE is a branched co-polymer of ethene and butane and since it is produced 


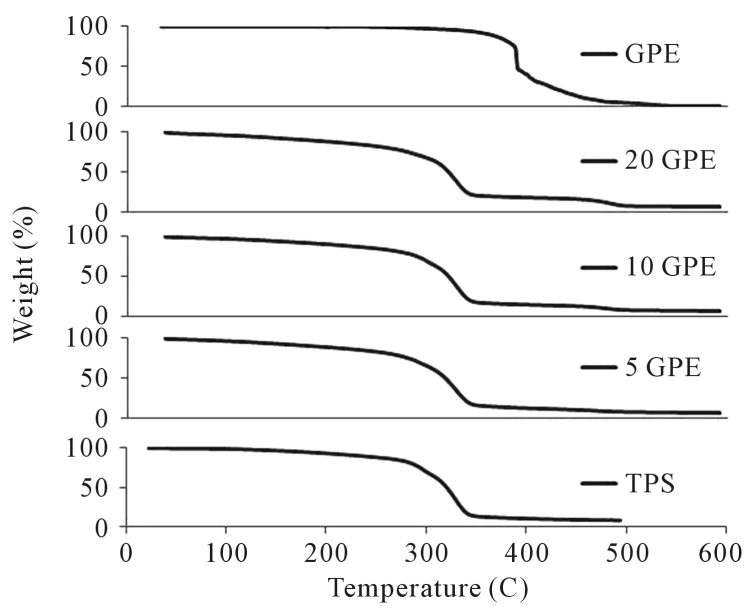

(a)

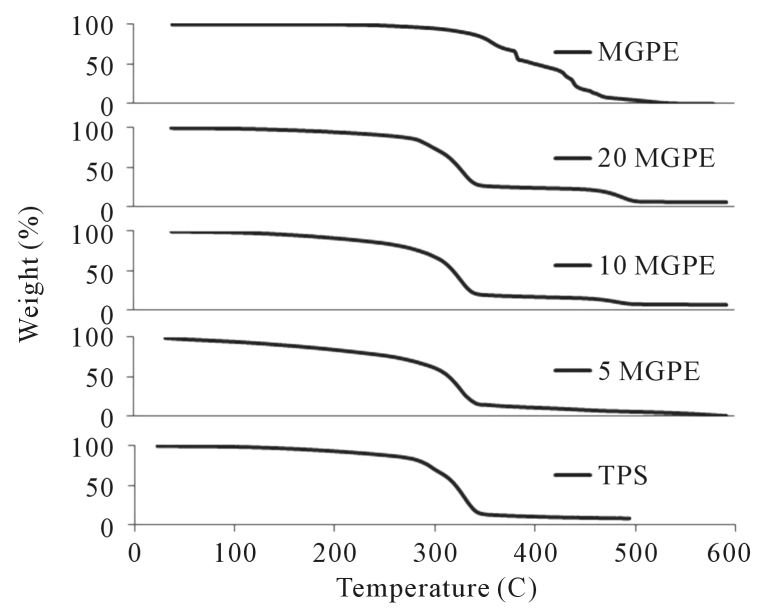

(b)

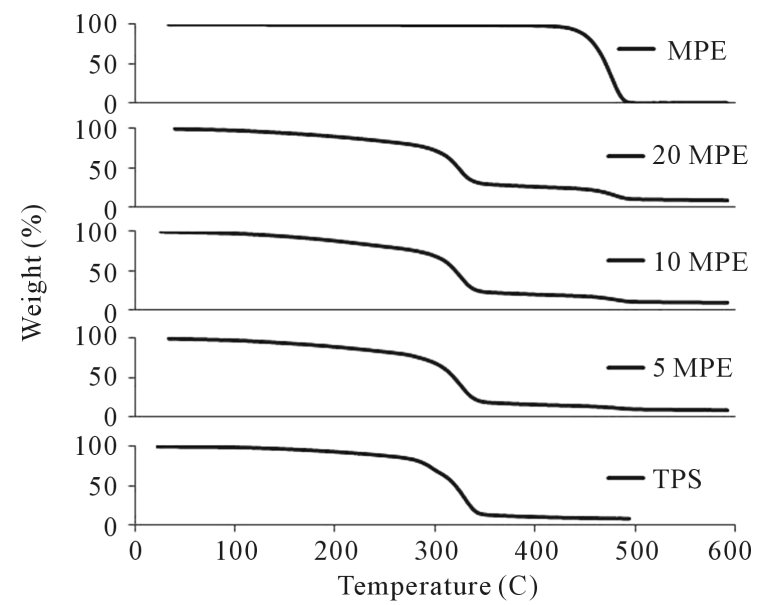

(c)

Figure 10. (a) TGA curves for TPS/GPE blends; (b) TGA curves for TPS/MGPE blends; and (c) TGA curves for TPS/MPE blends.

Table 3. Data from derivative TGA curves.

\begin{tabular}{|c|c|c|c|}
\hline Sample & $\mathrm{T}_{5 \%}\left({ }^{\circ} \mathrm{C}\right)$ & Starch $\mathrm{T}_{\max }\left({ }^{\circ} \mathrm{C}\right)$ & $\mathrm{PE} \mathrm{T}_{\max }\left({ }^{\circ} \mathrm{C}\right)$ \\
\hline TPS & 182 & 329 & N/A \\
\hline GPE & 337 & N/A & 388 \\
\hline MGPE & 304 & N/A & 381 \\
\hline MPE & 435 & N/A & 476 \\
\hline 5 GPE & 128 & 328 & 470 \\
\hline $10 \mathrm{GPE}$ & 143 & 330 & 480 \\
\hline $20 \mathrm{GPE}$ & 123 & 328 & 482 \\
\hline 5 MGPE & 97 & 330 & 480 \\
\hline $10 \mathrm{MGPE}$ & 163 & 326 & 482 \\
\hline 20 MGPE & 199 & 328 & 488 \\
\hline $5 \mathrm{MPE}$ & 139 & 326 & 482 \\
\hline $10 \mathrm{MPE}$ & 139 & 326 & 480 \\
\hline $20 \mathrm{MPE}$ & 145 & 324 & 478 \\
\hline
\end{tabular}




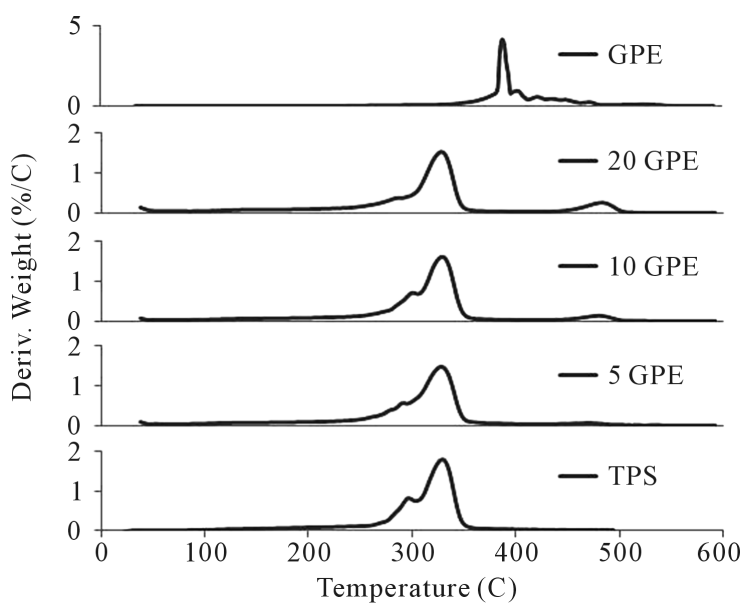

(a)

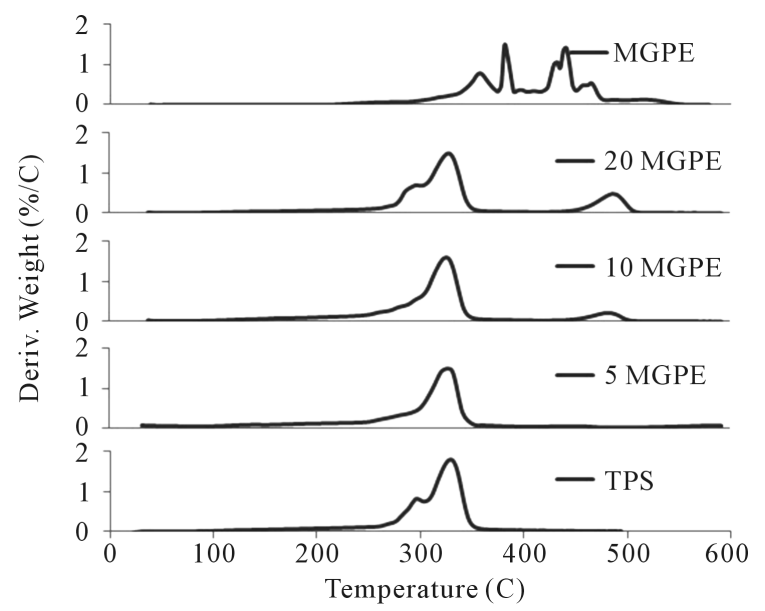

(b)

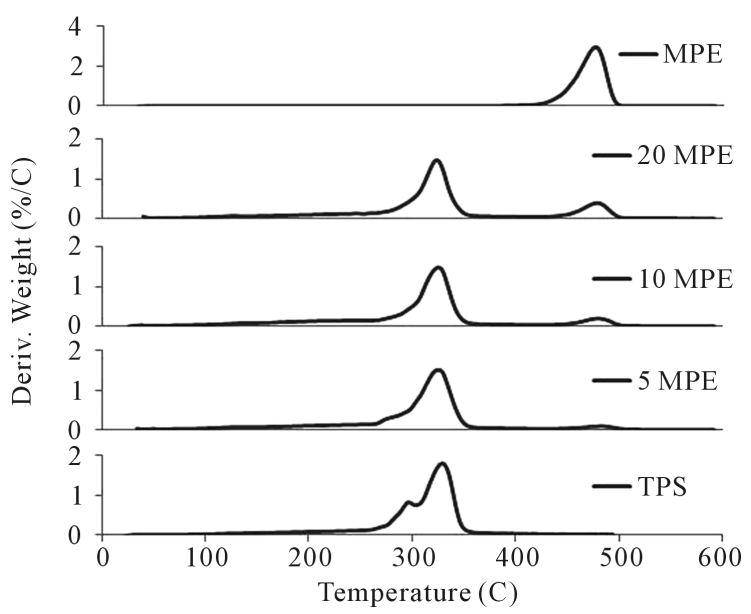

(c)

Figure 11. (a) Derivative TGA curves for TPS/GPE blends; (b) Derivative TGA curves for TPS/MGPE blends; and (c) Deriative TGA curves for TPS/MPE blends.

from a natural source the chain length and branching amount vary considerably, resulting in a wide range of degradation temperatures. However, in the case of the GPE and MGPE samples blended with TPS, the degradation temperature range was reduced and shifted to approximately $480^{\circ} \mathrm{C}$ from $380^{\circ} \mathrm{C}$. One possible explanation could be that starch char remaining in the sample absorbed heat and limited heat transfer to PE, thus increasing the temperature at which PE degraded.

\subsection{Water Absorption}

Results of water absorption testing of all starch blended samples, done at $100 \%$ relative humidity and room temperature, are shown in Figure 12. TPS is shown as a reference and the value for TPS water absorption (66\%) is comparable to the literature value (62\%) for glycerol plasticized (50 wt\%) TPS [23]. Adding polyethylene had the effect of significantly reducing water absorption below the value of TPS for all PE samples. This result is supported by the classical theory for a polymer blend that predicts the diffusion coefficient and moisture absorption of a hydrophilic polymer, stating that water absorption of the polymer blend is dependent on the weight fraction of TPS, weight fraction of hydrophobic polymer, the thermodynamic interaction energy between TPS and the hydrophobic polymer, and their respective diffusion coefficients [24]. Also, the water absorption value for all samples decreased as the amount of PE increased from 5\% to 20\%, except for the GMPE sample (discussed below). Again, this observation is explained classical theory which predicts the diffusion coefficient and water absorption of a polymer blend will decrease as the weight fraction of hydrophobic polymer increases. 


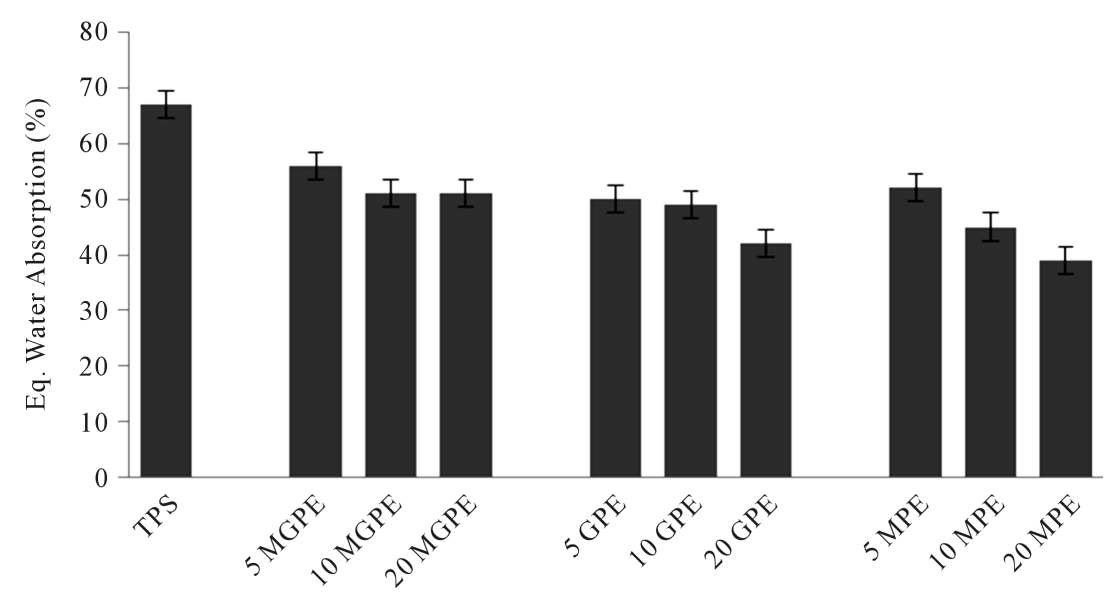

Figure 12. Water absorption at equilibrium for TPS and formulations with 95\% confidence intervals.

The MGPE samples displayed higher water absorption than the GPE and MPE formulations; a number of possible explanations exist for this observation. It is known that MAH causes starch destruction at high temperatures [21]; however, no evidence of starch destruction was found in the TGA results. Another possible explanation is that MGPE interfered with starch plasticization during extrusion, leaving pits and unplasticized granules where water can pass through. Evidence for this explanation is provided by the SEM images which contain more unplasticized granules for the MGPE samples than the MPE and GPE samples. Also, it is possible that MAH bonded with starch, preventing starch plasticization. This effect was the most pronounced in the 20 MGPE sample since more PE and MAH was available to interfere with starch plasticization and this may explain why the 20 MGPE sample had higher water absorption than the 10 MGPE sample.

The MPE samples displayed the lowest average water absorption of all three sample types tested. These samples exhibited better plasticization and thus lower water absorption than the MGPE samples. Also, the MPE samples showed better interfacial adhesion than the GPE samples. All this phenomena is attributed to lower activation energy of polymer blends which facilitates better interface and reduced water sensitivity.

\section{Conclusion}

Novel TPS formulations with green and common PE were developed through melt blending and reactive extrusion facilitated by MAH and DCP. The effects of different contents of GPE and PE were studied for physicchemical properties while maintaining glycerol level at constant levels. Also studied was effect of maleated GPE and PE over a range of concentrations and comprehensive morphological, thermal and hygroscopic analyses demonstrated some predicted and also novel results. SEM micrographs consistently showed some unplasticized areas owing to one-feeder feeding system which is a common drawback of in-situ extrusion processing. SEMs also showed phase separation involving virgin GPE and TPS, whereas polymer blend of maleated GPE and TPS was more homogeneous. Same was true of common PE formulations. FTIR data supported the fact that MAH, in the presence of DCP, could be used as a potential compatibilizer for GPE-TPS systems. During thermal studies, an interesting phenomena of a wide degradation temperature range was observed for neat GPE and MGPE polymers which largely owes to their distinct chemical composition containing branched co-polymers of ethane and butane. However, TPS blends of these polymers exhibited markedly shifted degradation temperature to around $480^{\circ} \mathrm{C}$ from $380^{\circ} \mathrm{C}$. In terms of moisture absorption, no statistical difference was observed among common PE and GPE formulations with TPS, although a significant reduced water absorption of up to $35 \%$ was experienced while using these polymers. The results of this study not only substantiate the earlier works but also warrant the use of new emerging biopolymers, like GPE, in the reactive extrusion formulations of TPS blends.

\section{Acknowledgements}

We would like to thank Natural Sciences and Engineering Research Council of Canada-Collaborative Research and Development Grants (NSERC-CRD) and Ontario Research Fund: Research Excellence (ORF-RE) programs for their financial support. 


\section{References}

[1] Reisser, J., Shaw, J., Wilcox, C., Hardesty, B.D., Proietti, M., et al. (2013) Marine Plastic Pollution in Waters around Australia: Characteristics, Concentrations, and Pathways. PLoS ONE, 8, e80466. http://dx.doi.org/10.1371/journal.pone.0080466

[2] Rouilly, A. and Rigal, L. (2002) Agro-Materials: A Bibliographic Review. Polymer Reviews, 42, 441-479.

[3] Babu, R.P., O’Connor, K. and Seeram, R. (2013) Current Progress on Bio-Based Polymers and Their Future Trends. Progress in Biomaterials, 2, 1-16. http://dx.doi.org/10.1186/2194-0517-2-8

[4] Kalambur, S. and Rivzi, S. (2006) An Overview of Starch-Based Plastic Blends from Reactive Extrusion. Journal of Plastic Film and Sheeting, 22, 39-58. http://dx.doi.org/10.1177/8756087906062729

[5] Chandra, R. and Rustgi, R. (1998) Biodegradable Polymers. Progress in Polymer Science, 23, 1273-1335. http://dx.doi.org/10.1016/S0079-6700(97)00039-7

[6] Cornell, H. (2003) Starch in Food: Structure, Function, and Applications. Woodhead Publishing Limited, CRC Press, Boca Raton, 211-240.

[7] Donald, A.M. (2003) Starch in Food: Structure, Function, and Applications. Woodhead Publishing Limited, CRC Press, Boca Raton, 156-184.

[8] Royal Society of Chemistry (2008) Carbohydrates. http://www.rsc.org/education/teachers/learnnet/cfb/carbohydrates.htm

[9] De Graff, R.A., Karman, A.P. and Janssen, L. (2003) Material Properties and Glass Transition Temperatures of Different Thermoplastic Starches after Extrusion Processing. Starch, 55, 80-86. http://dx.doi.org/10.1002/star.200390020

[10] Forssell, P., Mikkilä, J., Suortti, T., Seppäl, J. and Poutanen, K. (1996) Plasticization of Barley Starch with Glycerol and Water. Journal of Macromolecular Science, Part A, 33, 703-715. http://dx.doi.org/10.1080/10601329608010888

[11] Shogren, R.L., Fanta, G.F. and Doane, W.M. (1993) Development of Starch Based Plastics-A Re-Examination of Selected Polymer systems in Historical Perspective. Starch, 45, 276-280. http://dx.doi.org/10.1002/star.19930450806

[12] Stepto, R.F.T. (2003) The Processing of Starch as a Thermoplastic. Macromolecular Symposium, 201, $203-212$. http://dx.doi.org/10.1002/masy.200351123

[13] Averous, L., Moro, L., Dole, P. and Fringant, C. (2000) Properties of Thermoplastic Blends: Starch-Polycaprolactone. Polymer, 41, 4157-4167. http://dx.doi.org/10.1016/S0032-3861(99)00636-9

[14] Shogren, R.L. (1996) Preparation, Thermal Properties, and Extrusion of High-Amylose Starch Acetates. Carbohydrate Polymers, 29, 57-62. http://dx.doi.org/10.1016/0144-8617(95)00143-3

[15] Nabar, Y., Raquez, J.M., Dubois, P. and Narayan, R. (2005) Production of Starch Foams by Twin-Screw Extrusion: Effect of Maleatedpoly(butylene adipate-co-terephthalate) as a Compatibilizer. Biomacromolecules, 6, 807-817. http://dx.doi.org/10.1021/bm0494242

[16] Dubois, P. and Narayan, R. (2003) Biodegradable Compositions by Reactive Processing of Aliphatic Polyester/ Polysaccharide Blends. Macromolecular Symposium, 198, 233-243. http://dx.doi.org/10.1002/masy.200350820

[17] Sain, M., Robert, J. and Martin, H. (2011) Modified Thermoplastic Starch from Ophiostomaulmi Polysaccharide Conversion. US Patent: 7943349, WO 2008154729 A1.

[18] Kalambur, S. and Rivzi, S. (2006) An Overview of Starch-Based Plastic Blends from Reactive Extrusion. Journal of Plastic Film and Sheeting, 22, 39-58. http://dx.doi.org/10.1177/8756087906062729

[19] Barlow, J.W. and Paul, D.R. (1984) Mechanical Compatibilization of Immiscible Blends. Polymer Engineering and Science, 24, 525-534. http://dx.doi.org/10.1002/pen.760240804

[20] Raquez, J.M., Nabar, Y., Srinivasan, M., Shin, B., Narayan, R. and Dubois, Ph. (2008) Maleated Thermoplastic Starch by Reactive Extrusion. Carbohydrate Polymers, 74, 159-169. http://dx.doi.org/10.1016/j.carbpol.2008.01.027

[21] Shujun, W., Jiugao, Y. and Jinglin, Y. (2005) Preparation and Characterization of Compatible Thermoplastic Starch/ Polyethylene Blends. Polymer Degradation and Stability, 87, 395-401. http://dx.doi.org/10.1016/j.polymdegradstab.2004.08.012

[22] Raquez, J.M., Degee, Ph., Nabar, Y., Narayan, R. and Dubois, Ph. (2006) Biodegradable Materials by Reactive Extrusion: From Catalyzed Polymerization to Functionalization and Blend Compatibilization. Comptes Rendus Chimie, 9, 1370-1379. http://dx.doi.org/10.1016/j.crci.2006.09.004

[23] Mathew, A.P. and Dufresne, A. (2002) Plasticized Waxy Maize Starch: Effect of Polyols and Relative Humidity on Material Properties. Biomacromolecules, 3, 1101-1108. http://dx.doi.org/10.1021/bm020065p

[24] Paul, D.R. (1984) Gas Transport in Homogenous Multicomponent Polymers. Journal of Membrane Science, 18, 75-86. http://dx.doi.org/10.1016/S0376-7388(00)85026-7 
Scientific Research Publishing (SCIRP) is one of the largest Open Access journal publishers. It is currently publishing more than 200 open access, online, peer-reviewed journals covering a wide range of academic disciplines. SCIRP serves the worldwide academic communities and contributes to the progress and application of science with its publication.

Other selected journals from SCIRP are listed as below. Submit your manuscript to us via either submit@scirp.org or Online Submission Portal.
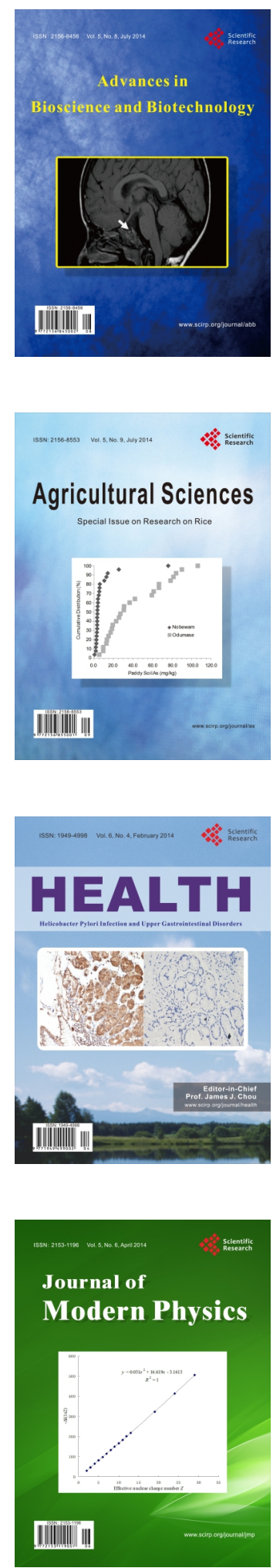
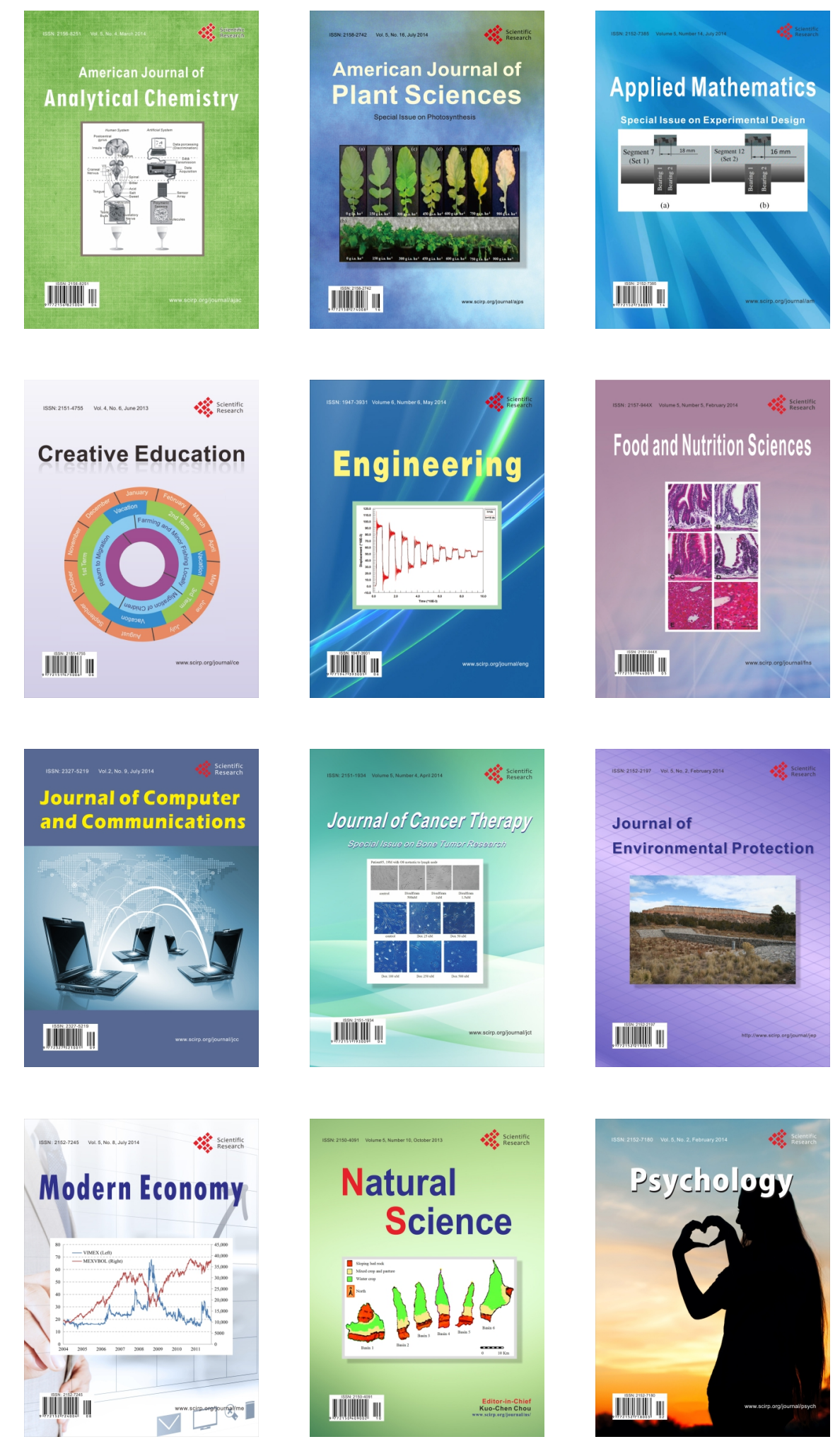